\title{
Reflexiones en torno a la autonomía tributaria de las entidades territoriales en el contexto del estado social de derecho
}

\author{
Omar Alfonso Ochoa Maldonado*
}

Ha de luchar el pueblo por su ley, igual que por

su muralla.

Heráclito de Efeso, Fragmento 44

\section{RESUMEN}

Uno de los cambios de mayor trascendencia que se consagró en la Constitución Política de 1991, fue el reconocimiento de ciertos niveles de autonomía en determinadas materias a las entidades territoriales, en procura de materializar el postulado de la descentralización administrativa como característica del modelo de Estado. Una de esas esferas en las que el Constituyente quiso que las entidades territoriales gozarán de un margen de autonomía en el ámbito de su jurisdicción, fue en temas de talante tributario, resaltándose que para el efecto, esté tipo de entidades están facultadas para decretar imposiciones tributarias, las cuales deben haber sido creadas o autorizadas previamente por el legislador en el ámbito nacional. El propósito palmario de este trabajo, es auscultar la naturaleza y alcance de la citada autonomía fiscal de las entidades territoriales, en el contexto del Estado Social de Derecho, como modelo jurídico político prohijado por el Constituyente y las repercusiones de esa relación simbiótica centro - periferia, en el devenir fiscal del Estado, frente al proceso de descentralización administrativa y la profundización de la democracia participativa, apelando para ello a la producción jurisprudencial generada en la materia.

\section{PALABRAS CLAVE}

Autonomía fiscal y territorial, impuestos, tributos territoriales, descentralización administrativa, jurisprudencia constitucional, corporaciones administrativas territoriales y contribuciones fiscales.

\footnotetext{
*Abogado con grado de Honor de la Universidad Nacional de Colombia. Especialista en Gestión Pública e Instituciones Administrativas, Universidad de los Andes; en Derecho Constitucional, Universidad Nacional de Colombia y en Derecho Privado Económico, Universidad Nacional de Colombia. Estudios en Filosofía, Pensamiento Político y Económico, Universidad Santo Tomás, Candidato a Magister en Derecho Económico Pontificia Universidad Javeriana. ochoaomar2006@yahoo.es
} 


\section{ABSTRACT}

One of the most significant changes that are enshrined in the Constitution of 1991 was the recognition of certain levels of autonomy in certain matters to local authorities, seeking to realize the postulate of administrative decentralization as a model of state property. One of those topics, where the Constituent Assembly that local authorities may enjoy a margin of autonomy in the area of jurisdiction, was in mood tax issues, emphasizing that the effect is kind of entities are entitled to decree enforcement tax, which must have been created or authorized in advance by the legislature at the national level. The blatant purpose of this work is to scrutinize the nature and extent of that fiscal autonomy of local authorities in the context of the rule of law, such as political and legal model fathered by the Constituent and the impact of this symbiotic relationship center - periphery , in becoming state prosecutor, to the process of administrative decentralization and the deepening of participatory democracy, calling for it to production generated jurisprudence in this area.

\section{KEYWORDS}

Fiscal autonomy and territorial taxes, land taxes, administrative decentralization, constitutional jurisprudence, Corporations Administrative territorial and tax contributions.

\section{INTRODUCCIÓN}

La tendencia marcadamente centralista que caracterizó la Constitución Nacional de 1886, fue objeto de un radical cambio con el advenimiento del pacto político del 1991, el cual se cimenta entre otros aspectos en la descentralización administrativa de competencias y la autonomía de las entidades territoriales en el marco de un Estado unitario.

Frente a ese particular, es pertinente adentrarnos en el estudio del alcance de la autonomía que la Constitución le reconoce a las entidades territoriales, en lo referente a facultad impositiva de exacciones dentro del ámbito de su jurisdicción, bajo el entendido que uno de los supuestos esenciales para poder pregonar con acierto el postulado de la descentralización administrativa de funciones, es contar con el insumo financiero básico que le permita a esta clase entes, la asunción de responsabilidades en materia de prestación eficiente y continua de servicios públicos, circunstancia que solamente se presenta cuando se cuentan con ingresos fiscales suficientes que les permitan desplegar con holgura el cúmulo de las atribuciones que tanto la Constitución como la ley le asignan a las citadas 
entidades territoriales.

En el contexto de la profundización de la democracia participativa, es pertinente abocar el estudio de los límites y contornos que dimanan del texto constitucional, frente al ejercicio autónomo de ciertas potestades impositivas en cabeza de los entes territoriales, las cuales deben estar acompasadas con la necesidad de un equilibrio macroeconómico en el contexto del Estado Social de Derecho.

Para esos efectos, este tipo de entidades cuentan con una serie de garantías de estirpe constitucional, tales como la participación en las rentas nacionales en los términos definidos en los artículos 356 y 357 de la Carta, desarrollados por conducto de las Leyes 715 de 2001 y 1176 de 2007, las cuales en su conjunto contienen el Sistema General de Participaciones a favor de los municipios, distritos y departamentos. Dicho ingreso se erige en el principal componente de los presupuestos de la mayoría de las entidades territoriales, ante la incapacidad endémica de generar ingresos propios que les permiten desempeñarse con solvencia en el cumplimiento de sus diferentes cometidos.

Su preponderancia constitucional ha sido reconocida por la jurisprudencia en los siguientes términos: "En síntesis, el municipio que antes aparecía relegado en un tercer plano, después de la nación y los departamentos, es hoy la célula fundamental de la estructura política y administrativa del Estado; lo que significa que el poder central no puede injerir en las gestiones y decisiones que se asuman a nivel local, de acuerdo con las competencias establecidas, pues si tal ocurre se compromete la autonomía administrativa, patrimonial y fiscal que la Constitución les reconoce a los entes territoriales descentralizados con las limitaciones señaladas en la Constitución y la ley." (Corte Constitucional. Sentencia C-506 de 1995. M. P. Dr. Carlos Gaviria Díaz.).

Igualmente, la Carta reconoce una serie de prerrogativas en cabeza de las entidades territoriales, las cuales en lo sustancial propenden por robustecer su accionar autónomo, tales como la especial protección de sus rentas asimilables a las garantías de las que goza la propiedad privada, entre otras.

Así las cosas, en el curso del presente ensayo, nos interesa adentrarnos en el análisis del alcance de la autonomía tributaria de esta clase de entes, para la imposición de tributos en el marco de su respectiva jurisdicción y la necesaria interacción que esa facultad presupone con el marco legislativo emanado del orden nacional, el cual morigera ese ámbito de la autonomía fiscal en el plano territorial. Pretendemos también en este trabajo, contextualizar esa coordinación entre instancias de diversos órdenes, en el discurso conceptual de naturaleza jurídica - política propia del Estado Social de Derecho, categoría que hoy en día permea todo el andamiaje estatal y que en cuanto tal, constituye referente de 
forzosa observancia al analizar cualquier actuación imputable al Estado.

Nuestra hoja de ruta será en un primer momento la referencia a las implicaciones de la categoría Estado Social de Derecho en materia tributaria y su relación con el margen de la autonomía constitucionalmente reconocida a las entidades territoriales, posteriormente, estudiaremos el alcance de la autonomía territorial en materia impositiva a la luz de la jurisprudencia constitucional proferida en la materia y finalmente plantearemos una serie de reflexiones conceptuales a título de colofón.

\section{Potestad tributaria del estado en el marco del Estado Social de Derecho}

Desde la Carta Magna de 1215, se perfiló como axioma que posteriormente devendría en consustancial a los Estados Constitucionales Modernos, aquél según el cual, la potestad para crear, modificar y suprimir tributos se encuentra radicada en el Congreso de la República o Parlamento (artículos 150 numeral 12 y 338 de la Constitución Nacional). El telos de tal atribución se enmarca en el discurso de la democracia tanto representativa como participativa en la cual, la decisión sobre las imposiciones fiscales debe recaer en el organismo de representación popular, dado en nivel general de afectación de este tipo de imposiciones.

La adscripción del poder de imposición tributario al órgano dotado de legitimidad democrática, encuentra expresión material en el Principio de Legalidad, conforme al cual no puede existir tributo sin previa ley que lo establezca, y cuyo fundamento primigenio fue el restringir la posible arbitrariedad de los gobiernos en la creación de nuevos tributos, garantizando la concurrencia del sentir del pueblo en la imposición de cualquier carga tributaria. En ese sentido, es claro que desde su origen y concepción, y en razón de su propia naturaleza, la Potestad Impositiva atribuida al Congreso no es omnímoda, en cuanto debe sujetarse a los intereses del conglomerado al que representa, en conciliación con los del Estado al que pertenece.

Es en ese contexto, las limitaciones al poder impositivo que devienen de la propia Carta Política, específicamente de la definición del Estado como "Social de Derecho" y los principios constitucionales en materia de tributación, los cuales se erigen en talanqueras de primer orden frente a la potestad tributaria que se ha reconocido en favor del Congreso. 
En efecto, la noción de Estado Social de Derecho comporta el reconocimiento de la persona como fin en sí misma en términos Kantianos, para lo cual el ordenamiento jurídico del Estado adquiere especial relevancia y reconocimiento, en materia de la protección efectiva de sus derechos fundamentales, de manera que, en ejercicio de su potestad tributaria, el legislador no puede establecer disposiciones e imponer cargas que amenacen vulnerar o efectivamente transgredan tales derechos, menos aun cuando es responsabilidad del Estado garantizar el acceso y disfrute de los mismos por parte de los asociados.

De otra parte, la categoría del Estado como Social de Derecho, también apareja la consagración de unos axiomas y catálogos de valores a partir de los cuales se deriva el sentido y finalidad de las demás normas del ordenamiento y el fundamento de la organización política, contexto en el cual el valor "Justicia Material" se erige como finalidad del orden político, económico y social, y su concreción en la justicia distributiva, como sustento del régimen impositivo o de tributación.

Siguiendo ese derrotero de interpretación, la Equidad del sistema tributario: "es un criterio con base en el cual se pondera la distribución de las cargas y de los beneficios o la imposición de gravámenes entre los contribuyentes para evitar que haya cargas excesivas o beneficios exagerados. Una carga es excesiva o un beneficio es exagerado cuando no consulta la capacidad económica de los sujetos pasivos en razón a la naturaleza y fines del impuesto en cuestión" (Corte Constitucional, Sentencia C-734 de 2002, M. P. Dr. Manuel José Cepeda Espinosa).

Ergo, es palmario que al momento de ejercer la potestad tributaria, el legislador, además de considerar la capacidad económica del contribuyente, tome en cuenta otra serie de factores que están inescindiblemente ligados respecto a quienes están llamados a contribuir, a partir de lo cual la equidad tributaria, en sus manifestaciones de equidad horizontal y de equidad vertical, materializa el principio de igualdad real y efectiva, al propender porque personas que se encuentren en las mismas condiciones sean gravadas de manera igual, y quiénes se encuentran en condiciones diferentes sean objeto de un tratamiento impositivo disímil, como una clara emanación del postulado de discriminación positiva y objetiva, prohijado por el ordenamiento superior.

Otro referente constitucional en materia tributaria, lo constituye el principio de progresividad, en su calidad de axioma relativo a la equidad vertical y en tanto se refiere a la distribución de la carga tributaria entre los diferentes sujetos destinatarios, según su propia capacidad contributiva, de tal suerte que las personas dotadas de una mayor capacidad contributiva, deben en consecuencia tributar en mayor grado, y quienes no tienen esa misma capacidad están llamados 
a realizar un menor esfuerzo fiscal. Sin perjuicio de lo anterior, la valoración del principio de progresividad del sistema puede realizarse también desde el punto de vista del destino y de los efectos del gasto público financiado con los recursos recaudados, bajo el entendido de que este último tiene un impacto relevante en la situación de los contribuyentes y, en términos generales, en los habitantes de un país, de manera que " la neutralidad, progresividad o regresividad del sistema en esta perspectiva más amplia se apreciaría comparando las condiciones económicas de los diferentes integrantes de la sociedad después de efectuado el gasto público". (Sentencia C-776 del 9 de septiembre de 2003, M.P. Dr. Manuel José Cepeda Espinosa).

En ese contexto, el concepto de "capacidad contributiva", surge como corolario que deviene de los principios reseñados, así como parámetro angular a partir del cual se estructura la justicia en la imposición y la distribución de la carga fiscal. Sobre el particular, señala el artículo 95 superior en su numeral 9 que "los ciudadanos están llamados a contribuir en condiciones de justicia y equidad", razón por la cual, el órgano que ostenta a nombre del Estado la facultad impositiva, está restringido a solamente exigir un aporte que consulte efectivamente la capacidad de pago del contribuyente.

De conformidad con las consideraciones precedentes, el poder de imperio en materia tributaria del cual es titular el Estado, se encuentra claramente delimitado por expresos mandatos de talante constitucional, y en ese sentido, su ejercicio por parte del legislativo, impone la estricta observancia de unas talanqueras constitucionales, so pena de que la disposición tributaria que se expida con desconocimiento de los citados límites, no supere el juicio de constitucionalidad al que se le someta en vigor.

Hechas las anteriores precisiones de orden conceptual, relativas al contexto dentro del cual se desenvuelve la facultad impositiva del Estado en su acepción "social de derecho", procedemos con el análisis en torno al alcance de la autonomía tributaria de las entidades territoriales.

\section{Autonomía tributaria de las entidades territoriales: entre la algarabía de la descentralización y la realidad de la restricción}

Para abordar la temática planteada, es necesario en primera instancia referirnos a los fundamentos constitucionales de la descentralización administrativa, el alcance de la autonomía fiscal de las entidades territoriales y la posibilidad de establecer tributos en el ámbito de su jurisdicción por parte de las entidades territoriales. 
El modelo jurídico - político adoptado por el Constituyente del año 1991, recoge el ideario planteado desde Herman Heller en torno a la categoría Estado Social de Derecho. Paralelo a ello, la Carta Política reconoce expresamente que Colombia se organiza en forma de República unitaria, con descentralización y autonomía administrativa de sus entidades territoriales, circunstancia que indica una marcada aspiración por dotar de un margen de maniobra relevante en ejercicio de las funciones a su cargo a este tipo de entidades.

En torno al modelo descentralizador frente al esquema anterior, se ha señalado que: "En esencia el objetivo de la descentralización en términos de búsqueda de la eficiencia del gasto se mantiene y se propone superar la visión simplista de la "descentralización como reparto" y hacerla participe del modelo de desarrollo" (Forero P. Clemente, 1997, pp. 11.). Desde esa perspectiva, una conclusión preliminar nos conduciría a señalar que si bien el esquema constitucional reconoce cierta autonomía a las entidades territoriales, la misma debe entenderse dentro del marco de un Estado unitario y no de corte federal.

Siguiendo esos derroteros de interpretación, en el plano de la autonomía territorial, la Carta reconoce una serie de competencias exclusivas radicadas en cabeza de las entidades de ese nivel, cuyo ejercicio no puede ser interferido por la órbita central, por cuanto en tal caso, ello implicaría una eventual violación al núcleo esencial de la autonomía territorial, constituido básicamente por los preceptos y atribuciones señaladas en el Titulo XI de la Constitución. No obstante, esa autonomía debe ejercerse dentro de los precisos límites que tanto la Constitución como la ley establezcan, por mandato expreso consignado en el artículo 287 superior y de contera dichas facultades deben desarrollarse con estricta sujeción a los principios de coordinación, concurrencia y subsidiariedad.

En ese orden de ideas, específicamente en materia fiscal, según los artículos 150 numerales 11 y 12 , en tono con el artículo 300 numeral 4 y el artículo 313 numeral 4 de la Carta, la competencia para establecer contribuciones fiscales 0 parafiscales recae exclusivamente en el legislador, no siendo sustentable la tesis de la soberanía fiscal de esta clase de entes. En efecto sobre el particular, ha señalado la doctrina:"Corresponderá entonces, al Congreso de la República crear tributos del orden territorial y señalar los aspectos básicos de cada uno de ellos, los cuales serán apreciados en casos concretos, en atención a su especificidad. Por su parte, las asambleas departamentales y los concejos municipales establecerán los demás elementos. Este análisis permite concluir, que la "soberanía fiscal" de las entidades territoriales no tiene fundamento constitucional." (Sánchez Torres, 2003, pp. 183).

En desarrollo del anterior razonamiento, las entidades territoriales no pueden establecer esa clase de contribuciones (fiscales o parafiscales), solamente están 
autorizadas para decretar y votar de conformidad con la Constitución y la ley, los tributos y contribuciones necesarios para el cumplimiento de las atribuciones y cometidos que se les han asignado en el ordenamiento, previamente señalada en la ley.

Dicha actuación del legislador a su vez se encuentra restringida ante la prohibición de conceder exenciones para tributos de las entidades territoriales (art. 294), la protección de sus rentas en las mismas condiciones que la propiedad de los particulares a que alude el artículo 362 y la reserva en cabeza de los municipios para gravar la propiedad inmueble (art. 317 C.P.). De esa forma, la autonomía territorial propende por una eficiente asignación de recursos por parte del Estado, para cumplir con las funciones que de conformidad con el modelo descentralizador deben asumir, consultando las necesidades particulares de cada escenario local.

Sobre ese particular, ha señalado la jurisprudencia constitucional: "En efecto, pese a que la Carta del 91 incrementó notablemente la capacidad tributaria de las entidades territoriales continúa supeditada a la ley que ha de ejercerse con estricta sujeción a los parámetros que en ella se fijen".

Sin embargo, el poder impositivo del Congreso se halla también limitado, en la medida en que no puede afectar los bienes y rentas de propiedad de las entidades territoriales, los cuales gozan de las mismas garantías que la propiedad y renta de los particulares, ni puede conceder exenciones ni tratamientos preferenciales en relación con los tributos de éstas. Dicha prohibición no se presenta con la cesión que en un momento dado haga el legislador a los municipios, del producto de un impuesto de carácter nacional, caso en el cual la atribución sigue siendo del Congreso, y éste podrá derogar el tributo; pero no puede disponer del producto ya cedido, el cual será libremente administrado por la entidad territorial beneficiaría. (Corte Constitucional. Sentencia C-506 de 1995. pp. 4).

No obstante lo anterior, el papel preponderante en esta materia lo tiene el legislador, con razón se ha afirmado que: "la libertad del legislador en esta materia es muy grande, de tal manera que las entidades territoriales gozan de pocas garantías institucionales que las protejan frente a las decisiones legislativas y les den un campo tributario propio" (Becker, 2003, pp. 42). En ese mismo sentido, se ha pronunciado el Consejo de Estado al señalar: "En la concepción del Estado social de derecho organizado en forma de república unitaria, el poder del legislador es pleno, puede crear o modificar impuestos como el de registro, así como regular lo atinente a elementos del mismo, así se trate de un impuesto departamental (...)", (Consejo de Estado, Sala Plena de lo Contencioso Administrativo, Sentencia 761 de 2000, M. P. Dr. Javier Díaz Bueno). 
Así las cosas, incluso la facultad en cabeza de las concejos y las asambleas para imponer contribuciones fiscales dentro del ámbito de su jurisdicción (287.3 y 314.3 C.P.), es una atribución derivada que está supeditada en todo caso a la ley, en este caso, la autonomía de las entidades territoriales se circunscribe a la adopción de la decisión en torno a establecer o suprimir los tributos autorizados genéricamente por la ley y a la libre administración de las rentas percibidas por esos conceptos dentro de la órbita de su jurisdicción (Sentencias proferidas por la Corte Constitucional, Sala Plena C-560 de 1995 M. P. Dr. Calor Gaviria Díaz y C232 de 1998 M. P. Dr. Hernando Herrera Vergara). Sobre el particular ha señalado el Consejo de Estado: "En este orden de ideas se observa, que la autonomía de que gozan las entidades territoriales, conlleva el derecho a definir la administración y disposición de sus recursos. La concreción de su ejercicio implica el desarrollo normativo de las previsiones contenidas en la ley, que deban ser reglamentadas por medio de actos administrativos emanados de las corporaciones de elección popular de dichas entidades; actividad para la cual las autoridades locales encuentran su límite propio en lo dispuesto en la Constitución y la ley; por lo que debe entenderse que la autonomía que les garantiza la norma superior, no es absoluta, conforme al principio de República Unitaria". (Consejo de Estado, Sala de lo Contencioso Administrativo Sección Cuarta, Fallo 7715 de 1997 Consejo de Estado, M. P. Dr. Julio Enrique Correa Restrepo).

Ergo, es evidente a la luz del razonamiento anterior que las entidades territoriales no gozan de un margen de maniobra institucional que les permite motu propio decretar contribuciones fiscales o parafiscales, sino que en materia fiscal tienen unas facultades derivadas, no originarias, que en todo caso deben supeditarse a las prescripciones que haya señalado previamente el legislador.

Como corolario de lo anterior tenemos que las corporaciones de representación popular de las entidades territoriales, están facultadas para decretar en el ámbito de su jurisdicción, contribuciones fiscales y parafiscales que previamente hayan sido creadas por el legislador y en esos eventos, la ley de creación puede dejar un amplío margen de maniobra para que los elementos configurantes de la obligación tributaria sean determinados en forma específica por la entidad territorial respectiva. En un reciente pronunciamiento, la Corte Constitucional se refirió a la temática sub examine, en los siguientes términos:

"Así las cosas, la jurisprudencia ha admitido que los elementos de la obligación tributaria sean determinados por las asambleas departamentales y los concejos distritales y municipales, pero dentro de unos parámetros mínimos que deben ser señalados por el legislador. Estos parámetros mínimos, según se desprende de la jurisprudencia, son dos: (i) la autorización del gravamen por el legislador, y (ii) la delimitación del hecho gravado con el mismo." (Corte Constitucional. Sentencia C035 de 2009. M. P. Dr. Marco Gerardo Monroy Cabra). 
Esa posición que hoy en día ostenta la calidad de imperante, es el resultado de un avance prolífico a nivel jurisprudencial, que ha matizado la concurrencia entre el Congreso de la República y las Asambleas Departamentales y Concejos Municipales y Distritales, en materia de la imposición de tributos en el ámbito territorial, destacándose que el legislador tiene un mayor margen de maniobra tratándose de impuestos del orden nacional respecto de los cuales debe señalar todos sus elementos: sujeto activo, sujeto pasivo, base gravable, tarifa, hecho generador, mientras que tratándose de tributos del orden territorial debe circunscribirse a señalar pautas, orientaciones y limitaciones generales para que sea la respectiva entidad territorial la que dote de contenido específico el tributo al decretarlo en el ámbito de su jurisdicción. Incluso se ha llegado a señalar en la Sentencia C-538 de 2002 que en el evento que el legislador detalle cada elemento del tributo territorial en la ley, restándole margen de maniobra a las entidades territoriales en ese sentido, se configuraría una violación al núcleo esencial de la autonomía que la Carta le reconoce en el plano fiscal a las entidades territoriales de modo que no se desvirtúe o desconozca tal prerrogativa.

Frente al avance jurisprudencial sobre la concurrencia entre el Congreso y las Corporaciones Administrativas Territoriales, en materia de imposición de tributos de ese orden, se ha señalado en Sentencia C-121 de 2006 lo siguiente: "Como puede apreciarse, paulatinamente la jurisprudencia vertida en torno del asunto de las competencias tributarias concurrentes del legislador y de las asambleas y concejos ha ido avanzando de la siguiente manera: (i) inicialmente la Corte hizo ver que la autonomía impositiva de los entes territoriales se encontraba subordinada tanto a la Constitución como a la ley. (Sentencias C-04 de 1993 y C467 de 1993, entre otras); (ii) más adelante señaló que aunque la facultad de las asambleas y concejos para imponer contribuciones no era originaria, sino que estaba subordinada a la Constitución y a la ley, las entidades territoriales gozaban de autonomía, tanto para la decisión sobre el establecimiento o supresión de impuestos de carácter local, autorizados en forma genérica por la ley, como para la libre administración de todos los tributos que hicieran parte de sus propios recursos (Sentencia C-506 de 1995 entre otras); (iii) posteriormente, la jurisprudencia sostuvo que los elementos del tributo podían estar determinados no sólo en la ley sino también en las ordenanzas departamentales o en los acuerdos municipales, de manera que al no señalar el legislador directamente dichos elementos, bien podían en forma directa hacerlo las Asambleas Departamentales y los Concejos Distritales o Municipales (Sentencia C-537 de 1995, entre otras); (iv) Sostuvo luego la Corporación en la Sentencia C-1097 de 2001 que "mientras en los tributos de linaje nacional el Congreso goza de poderes plenos, en lo tocante a los tributos territoriales su competencia es compartida con las asambleas y concejos"; y en la Sentencia C- 227 de 2002 precisó que las leyes que tan solo autorizan a establecer tributos a las entidades territoriales, solo debían ocuparse de los 
elementos básicos de los tributos. (v) Por último, en Sentencia C-538 de 2002 la Corte consideró que si bien era cierto que en relación con los tributos nacionales el legislador debía fijar todos los elementos, esto es, sujeto activo, sujeto pasivo, hechos y bases gravables y tarifas, también lo era que "frente a los tributos territoriales el Congreso no puede fijar todos sus elementos porque estaría invadiendo la autonomía de las entidades territoriales"; empero, en este caso el legislador puede "señalar ciertas pautas, orientaciones y regulaciones o limitaciones generales", para el ejercicio de la facultad impositiva territorial."

Desde esa óptica tenemos que tratándose de leyes que crean tributos, es menester que por mandato del artículo 338 superior, el Congreso de la República, determine los elementos que conforman la obligación tributaria con mayor nivel de especificidad, no ocurre lo mismo cual la ley autoriza el tributo para que en el ámbito territorial se definan las particularidades del mismo, ostentando esta última disposición un carácter más general que la anterior (Corte Constitucional. Sentencia C-084 de 1995. M. P. Dr. Alejandro Martínez Caballero).

En un pronunciamiento reciente, la Corte declaró la inexequibilidad de una disposición que restringía la autonomía territorial en materia fiscal, en la Ley 1005 de 2006 que limitaba el recaudo de especies venales por parte de los organismos de tránsito del orden territorial, por cuanto en su sentir: "la restricción impuesta no deja ni siquiera un margen mínimo al recaudo de tarifas por concepto de derechos de tránsito dado que cercena en su totalidad la fuente de la cual el ente territorial recibe las rentas propias, de modo que la medida desatiende la autonomía de las entidades territoriales que, como garantía institucional tiene un núcleo esencial indispensable para el legislador." (Corte Constitucional. Sentencia C-318 de 2010. M. P. Gabriel Eduardo Mendoza).

Nótese cómo la tendencia cada vez más secular en materia jurisprudencial, es hacia el reconocimiento de un ámbito cada vez mayor de la autonomía fiscal de las entidades territoriales, en materia no solamente de administración y recaudo de fuentes endógenas de financiamiento, sino en la determinación de los elementos que configuran un tributo en el ámbito de su jurisdicción, el establecimiento o supresión del mismo, siempre bajo la égida de la creación o autorización impartida por el legislador.

Ahora bien, efectuadas las anteriores precisiones conceptuales, cabe resaltar que si bien las entidades territoriales son beneficiarias de los monopolios estatales rentísticos, tampoco en ese frente de acción gozan de un amplio margen de maniobra, por el contrario están supeditas a los mandatos de talante legal que regulan esas temáticas. Sobre este aspecto adicional a lo señalado en precedencia, debe indicarse que la Carta ha configurado un régimen especial y propio para los citados monopolios, el cual según la jurisprudencia constitucional 
contiene los siguientes elementos: "De esta manera, el artículo 336 superior establece que: i) todo monopolio rentístico busca satisfacer una necesidad de interés público ii) debe constituir un arbitrio rentístico y iii) es necesaria la indemnización previa a los individuos que se vean privados de su ejercicio. Además, esa misma disposición iv) predetermina la destinación de algunas de esas rentas y v) obliga al Gobierno a liquidar esos monopolios si no demuestran ser eficientes" (Corte Constitucional, Sala Plena. Sentencia C-169 de 2004. M. P. Dr. Alvaro Tafur Galvis. pp.4).

El mismo artículo 336 indica una expresa reserva de ley para el establecimiento de monopolios rentísticos, lo cual descarta de plano la posibilidad de que las entidades territoriales puedan establecer este tipo de monopolios. En efecto, "También la jurisprudencia, a partir del texto constitucional vigente, ha hecho énfasis en que la creación, organización y funcionamiento de los monopolios corresponde a la ley" (Corte Constitucional, Sala Plena. et. al. pp. 4)., como manifestación de las anteriores atribuciones tenemos la Ley 100 de 1993 que en su artículo 285 establece la explotación monopólica en beneficio del sector salud de las modalidades de suerte y azar, así como la Ley 643 de 2001 que fija el régimen propio del monopolio rentístico de los citados juegos.

Por lo anterior, en desarrollo de los preceptos constitucionales, exclusivamente el legislador puede establecer arbitrios rentísticos con carácter de monopolios, los cuales deben tener un fin de intereses públicos, así como determinar los parámetros para su manejo y administración. La Constitución no ha señalado de antemano que tipo de actividades son pasibles de ser declaradas como monopolios rentísticos, situación que le compete al legislador con sujeción a las citadas reglas contenidas en el artículo 336 superior.

Frente a las entidades territoriales, cabe señalar que bien podría un legislador en ejercicio de las competencias señaladas en precedencia, determinar que sean éstas las titulares de las rentas que se perciban por concepto de monopolios rentísticos, en este evento este tipo de entes tendrían el derecho exclusivo a beneficiarse de este tipo de rentas, por disposición que la ley efectuare sobre el particular.

Cabe resaltar en relación con esta última hipótesis que el artículo 362 de la Carta, incluye dentro de las rentas que gozan de especial protección, las provenientes de monopolios de las entidades territoriales, situación que se presentaría en el evento en que el legislador haya previamente definido a esta clase de entidades como beneficiarias del arbitrio rentístico respectivo.

Habida cuenta de las anteriores consideraciones, es improcedente el establecimiento de monopolios estatales como arbitrio rentístico por parte de las 
entidades territoriales motu propio, toda vez que se trata de una materia que expresamente tiene reserva de ley.

En el contexto de la realidad descrita, cabe señalar adicionalmente el cúmulo de restricciones fiscales que constituyen un agravante a la problemática de la autonomía territorial. En efecto, el proceso tendiente a la descentralización administrativa de funciones del centro a la periferia, propende por la creación de mecanismos que coadyuven eficientemente a la distribución del ingreso entre las diferentes regiones en condiciones de equidad, circunstancia que implica como corolario necesario, el traslado de los recursos fiscales que permitan que las entidades territoriales cumplan adecuadamente con los cometidos que les han sido conferidos tanto por la Constitución como por la ley. Bajo el supuesto que el Municipio es el responsable directo por la prestación de los servicios públicos en el ámbito de su jurisdicción y ante la tozuda realidad de unos famélicos ingresos propios por parte de la mayoría de entidades territoriales, se erigen como un elemento decisivo para la conformación de los presupuestos en el ámbito regional, las transferencias que la Nación efectúa a las diferentes entidades territoriales a través del Sistema General de Participaciones creado por el Acto Legislativo 01 de 2001 y desarrollado por la Ley 715 de 2001.

Cabe señalar que el texto constitucional original, contenido en los artículos 356 y 357 del texto Constitucional, hacía referencia a la participación de los Municipios en los ingresos corrientes de la Nación y al situado fiscal señalándose expresamente frente a éste último que "aumentará anualmente hasta llegar a un porcentaje de los ingresos corrientes de la Nación que permita atender adecuadamente los servicios para los cuales está destinado. Con este fin, se incorporarán a él la retención del impuesto a las ventas y todos los demás recursos que la Nación transfiere directamente para cubrir gastos en los citados niveles de educación." De la misma forma, en torno a la participación municipal se indicaba que la misma debería crecer anualmente porcentualmente en relación con los ingresos corrientes de la Nación.

El mencionado Acto Legislativo 01 de 2001, estableció que el crecimiento de las citadas transferencias estaría en lo sucesivo atado a la inflación y unos puntos adicionales dependiendo del crecimiento económico medido en términos del comportamiento del indicador Producto Interno Bruto PIB, circunstancia que a la postre implicó un ritmo menor de crecimiento de las transferencias territoriales en relación con el querer original del Constituyente. Dicha circunstancia planteada como transitoria, fue reforzada por el Acto Legislativo 04 de 2007 que mantiene la misma dinámica de crecimiento atado a la inflación y al PIB, señalándose además un esquema de monitoreo por parte de la Nación hacia las entidades destinatarias del Sistema General de Participaciones y la definición de unas coberturas mínimas antes de inversión, surgiendo adicionalmente la posibilidad que la Nación desplace 
a la entidad territorial y ejecute a nombre de la misma la partida respectiva, circunstancias todas éstas que socavan directamente el núcleo esencial de la autonomía territorial.

\section{A título de conclusión: el paulatino proceso de reconocimiento de la autonomía tributaria en el plano territorial}

Uno de los pilares sobre los cuales se soporta el andamiaje de la democracia participativa como fórmula jurídico política acogida por el Constituyente del año 1991, es el robustecimiento de la descentralización administrativa en el plano territorial, la cual permite no solamente la asunción de responsabilidades directas por parte de las autoridades locales, sino que propicia espacios para profundizar el ideario democrático en la provincia y crear de esa forma sentido de pertenencia frente a los habitantes de las regiones como actores activos en la construcción del quehacer de lo público, en un esquema que de vieja data se ha caracterizado por el exclusionismo centralista.

Tratándose específicamente del manejo fiscal de las entidades territoriales, cabe destacar que la descentralización de funciones del centro a la periferia, debe ir necesariamente acompasada con el traslado de recursos y el fortalecimiento financiero de las entidades territoriales, toda vez que sin el sustrato económico no es procedente la radicación de funciones en cabeza de estos entes. En últimas, la materialidad de la descentralización administrativa está dada por la capacidad financiera de las entidades territoriales para el cabal cumplimiento de sus cometidos.

En ese contexto, cobra especial relevancia el ámbito de la autonomía fiscal reconocida en la Constitución a esta clase de entidades, aspecto frente al cual surge palmariamente el racionamiento según el cual, por tratarse de un Estado unitario, se encuentra descartada de plano la tesis de la soberanía fiscal territorial. En esa línea de pensamiento, el Consejo de Estado ha señalado: "El principio de descentralización que la Constitución Política instituye como pilar fundamental del Estado Social de Derecho, que se traduce en la autonomía que para la gestión de sus particulares intereses se reconoce a favor de las entidades territoriales, debe sujetarse a los límites impuestos por el Constituyente en la Carta Política, y a las disposiciones legales, tal como lo establece el citado artículo 287 de la C.P. Súmase a lo expuesto que la efectividad de los principios de unidad y autonomía, que tienen igual valor constitucional, exige su armonización concreta de modo que se preserve el principio unitario proclamado en la Constitución Política como pilar fundamental de la organización del Estado Colombiano, al tiempo que garantice la realización del núcleo esencial de la autonomía de las entidades territoriales, asegurándoles su derecho de regular los que se han denominado sus propios y particulares intereses. De todo lo anterior se colige que, la potestad impositiva de 
las entidades territoriales no se erige en un poder ilimitado." (Consejo de Estado, Sala de lo Contencioso Administrativo Sección Primera, Sentencia 6345 de 2001 Consejo de Estado, M.P. Camilo Arciniegas Andrade).

No obstante, existe una denodada preocupación plasmada en la Constitución, para restringir el ámbito de la intervención central en ciertos asuntos exclusivamente internos de los entes territoriales en materia impositiva y de manejo endógeno de recursos fiscales.

En efecto, las rentas de esta clase de entidades gozan de la misma protección que la propiedad privada de los particulares y solamente pueden ser transferidas a favor de la Nación transitoriamente en caso de guerra exterior (art.362 C.P.). En esa misma línea, el legislador no puede establecer exenciones respecto a las rentas de las entidades territoriales (art. 294 C.P.) y solamente el municipio como eje medular de la organización administrativa, es el llamado a gravar la propiedad inmueble (art. 317 C.P.).

Por otro lado, las Asambleas Departamentales y los Concejos Municipales o Distritales, están facultados para establecer los tributos necesarios en el ámbito de la jurisdicción territorial (Véase arts. 287 numeral 3, 294, 295, 300-4 y 313-4). Dicha facultad impositiva no es omnímoda sino que por el contrario se encuentra sujeta a la Constitución y la ley, de tal suerte que la autonomía que se proclama en el texto está supeditada al margen que el legislador le permita en la práctica, resultado lógico en el contexto de un Estado unitario.

Es en el curso de esa relación simbiótica entre el Congreso y las Corporaciones Administrativas de elección popular en el plano territorial, que se han delineado posiciones disímiles en cuanto a su tratamiento jurisprudencial, desde la negación de cualquier facultad en materia impositiva que no fuere expresamente regulada en la ley a estos órganos colegiados, hasta el reconocimiento expreso de que el legislador al autorizar o crear tributos territoriales, debe diferir un margen de maniobra relevante al respectivo ente territorial, para que de acuerdo a sus especificidades, establezca las condiciones concretas de la obligación tributaria, so pena de quebrantar el núcleo esencial de la autonomía fiscal territorial que se eleva a la categoría de derecho con reconocimiento de estirpe constitucional.

Así las cosas, si bien la creación de tributos territoriales es una potestad exclusiva del Congreso de la República, el decreto, el establecimiento, la supresión, la administración, su utilización y las particularidades propias del tributo, son del resorte exclusivo del ente territorial, sin injerencia heterónoma proveniente del sector central.

Sobre la base de unos lineamientos generales plasmados en la ley que son de 
forzosa observancia, surge un amplío margen de acción de los entes territoriales, respecto al manejo fiscal de sus ingresos y el destino de los mismos en el cumplimiento de las responsabilidades a su cargo en el contexto de la descentralización administrativa; así lo ha reconocido la reciente jurisprudencia constitucional (Sentencias C-035 de 2009 y C-318 de 2010), fruto de un proceso evolutivo que ha privilegiado el despliegue interno de competencias sobre la imposición exógena de las mismas.

Esa tendencia a robustecer las competencias fiscales de las entidades territoriales, es consecuente con el ideario del Estado Social de Derecho que persigue no solamente el reconocimiento formal de los derechos, sino el desarrollo de los mecanismos concretos para su efectiva realización, los cuales en materia de ingresos fiscales territoriales deben propender por su manejo autónomo e independiente, en aras de profundizar el esquema democrático y participativo que inspira el texto constitucional.

\section{REFERENCIAS BILIOGRÁFICAS}

Becker A. (2003) Ordenamiento Territorial. Reivindicación de la Descentralización para el desarrollo. GTZ -Fescol.

Colombia, Consejo de Estado (1997), "Fallo 7715", M. P. Correa Restrepo, J. E., Bogotá.

Colombia, Consejo de Estado (2000), "Sentencia 761", M. P. Díaz Bueno, J., Bogotá.

Colombia, Consejo de Estado (2001), "Sentencia 6345”, M. P. Arciniegas Andrade, C., Bogotá.

Colombia, Corte Constitucional (1995), "Sentencia C-084", M. P. Martínez Caballero, A., Bogotá.

Colombia, Corte Constitucional (1995), "Sentencia C-506”, M. P. Gaviria Díaz, C., Bogotá.

Colombia, Corte Constitucional (1998), "Sentencia C-232", M. P. Herrera Vergara, H., Bogotá.

Colombia, Corte Constitucional (2002), "Sentencia C-734", M. P. Cepeda Espinosa, M. J., Bogotá.

Colombia, Corte Constitucional (2003), "Sentencia C-776", M. P. Cepeda 
Espinosa, M. J., Bogotá.

Colombia, Corte Constitucional (2004), "Sentencia C-169", M. P. Tafur Galvis, A., Bogotá.

Colombia, Corte Constitucional (2006), "Sentencia C-121", M. P. Monroy Cabra, M. G., Bogotá.

Colombia, Corte Constitucional (2009), "Sentencia C-035”, M. P. Monroy Cabra, M. G., Bogotá.

Colombia, Corte Constitucional (2010), "Sentencia C-318", M. P. Mendoza G. E., Bogotá.

Forero p. Clemente y otros. (1997) Descentralización y Participación Ciudadana. Tercer Mundo Editores. Bogotá.

Plazas Vega, M. A. (1998). El Impuesto Sobre El Valor Agregado. (2da Ed.). Editorial Témis S.A. Bogotá.

Sánchez Torres C. A. (2003, agosto). El Concepto Constitucional de Autonomía Fiscal y sus alcances Legales y Jurisprudenciales en Colombia a partir de la Constitución Política de 1991. Revista de Estudios Sociojurídicos. Universidad del Rosario, Volumen 005 No. 001, pp. 172 a 209.

Valdés Costa, R. (1992) Instituciones de Derecho Tributario. Ediciones Depalma. Buenos Aires. 